Article

\title{
New Kinds of (Ab)normal?: Public Pedagogies, Affect, and Youth Mental Health in the Digital Age
}

\author{
Simone Fullagar* (D), Emma Rich and Jessica Francombe-Webb \\ Department for Health, University of Bath, Claverton Down, Bath BA2 7AY, UK; E.Rich@bath.ac.uk (E.R.); \\ j.m.francombe-webb@bath.ac.uk (J.F.-W.) \\ * Correspondence: s.p.fullagar@bath.ac.uk; Tel.: +44-(0)1225-385-654
}

Received: 19 July 2017; Accepted: 28 August 2017; Published: 31 August 2017

\begin{abstract}
Academic, policy, and public concerns are intensifying around how to respond to increasing mental health problems amongst young people in OECD countries such as the UK and Australia. In this paper we make the case that public knowledge about mental health promotion, help-seeking, support and recovery can be understood as an enactment of public pedagogy-as knowledge practices and processes that are produced within and beyond formal spaces of learning. We explore the question of how new pedagogic modes of address are produced through digital technologies-social media, gamified therapies, e-mental health literacy, wearable technology—as they invite particular ways of knowing embodied distress as "mental illness or ill health." The rapid growth of formal and informal pedagogical sites for learning about youth mental health raises questions about the affective arrangements that produce new kinds of $(\mathrm{ab})$ normal in the digital era. Through a posthumanist perspective that connects critical mental health studies and public pedagogy, this paper offers an original contribution that theorises pedagogic sites within the cultural formation of public-personal knowledge about mental (ill) health.
\end{abstract}

Keywords: public pedagogy; youth mental health; affect; digital technology; social media; posthumanist; mental health literacy

\section{Introduction}

There has been increasing recognition from a diverse range of perspectives and voices that mental ill health is now a global public issue, particularly for young people who are identified as an at-risk population (McManus et al. 2016; World Health Organisation 2017). Policy discourses-in countries such as the United Kingdom-emphasise the social and economic costs of a growing youth mental health "crisis" as they mobilise techno-optimism via digital solutions. The NIH National Institute for Mental Health claim that 'Technology has opened a new frontier in mental health support and data collection.' In this context digital communication and technology are positioned unproblematically as new pedagogic tools for increasing public awareness, mental health literacy and individual help-seeking. What is not often acknowledged in these policy calls are more complex meanings that shape digital representations of "mental ill health" for young people across diverse sites of learning. Hence, this article speaks to the need for more critical insights into how "digital tools" interrelate with pedagogical modes of address to powerfully shape how young people come to 'know' what mental ill health 'is,' and how to 'act' in the context of diagnostic psy-cultures (Rose and Abi-Rached 2013). Our interest in digital technology and public pedagogy stems from a concern with understanding the sociomaterial relations that shape everyday learning about youth mental health knowledge-engaging with recommended apps, searching official and unofficial websites, reading or creating personal blogs, tweets, Instagram images, etc. We consider these questions by drawing upon insights from posthumanist thinking to theorise how public pedagogy is thoroughly entangled with digital 
technologies, youth subjectivities and learning-knowing about embodied distress. By examining how different pedagogical sites of learning about youth mental ill health are producing new forms of (ab)normal in the digital era, we offer an original contribution that connects debates across critical mental health, public pedagogy and posthumanism.

Speaking of the digital transformation of public space and the emergence of new cultural sites of pedagogy, Giroux (2004, p. 74) points to the intensification of corporate power and how "knowledge and desire are inextricably connected" to new "modes of pedagogical address". Digital mental health technologies are also sites through which young people actively produce-consume meanings about distress as they navigate the intensified commercial relations of microcelebrity culture and performativity (Hendry et al. 2017). In this article we take up the question of how new pedagogic modes of address are produced through digital technologies as they enact and circulate contemporary ways of knowing and doing embodied distress_thoughts, feelings, desires_as "mental illness or ill health." However, we depart from Giroux's focus on pedagogy as ideology to outline a conceptual framework informed by critical post-humanism in order to connect current debates on public pedagogy with those in digital mental health. Bringing these often separate literatures together provides a productive means of examining the entanglement of subjectivities, affects and technologies in the cultural formations of public-personal knowledge about mental (ill) health. This approach contributes to new ways of theorising the sociomaterial relations that entangle young people's learning about distress through what Slaby et al. (forthcoming) have called an affective arrangement (please see (Fullagar et al. forthcoming) in this issue for an example of how we have applied this framework to examine the implications of mental health 'apps' for young users).

Through a focus on affects we pursue critical questions concerning the limitations of current onto-epistemological assumptions informing mental health research, as well as what the implications of digital mental health practices might be for young people. As Swist and Collin (2017, p. 7) have argued in relation to the digital rights of young people, "[ $\mathrm{t}]$ echnology not only diversifies and intensifies communication, it is reconfiguring human expression and interaction at the level of the self and society". We consider how relations of affect circulate in ways that blur ostensible boundaries between 'formal' and 'informal' pedagogic sites—schools, health promotion, clinical information-and across a diverse range of digital practices (social media, apps, web self-assessments, etc.) within the biopolitical assemblage of health and illness (Duff 2014). Rather than assume digital mental health technologies are easily categorised as either helpful or harmful innovations (see McCosker 2017), this approach situates analyses in the contemporary moment where ideas of (ab)normal personhood are mediated by expert diagnostic cultures (DSM-V criteria, digital self-assessment) (Fullagar 2017; Rose and Abi-Rached 2013). In this way we disrupt the private/public, formal/informal, expert/lay, pedagogue/learner, reason/emotion and mind/body dualisms that have underpinned traditional pedagogic models of mental health literacy and promotion, and in doing so contribute to a material-discursive analysis of public pedagogy.

Despite the lack of more critical perspectives in policy and promotion, there is a growing social science critique of how biomedical discourses of mental ill health are digitally mediated and circulate individualised, normative identities that bracket out differences and inequities (Fullagar 2008; Maturo et al. 2016). Scholars within digital sociology and science and technology studies have problematised the way that particular health technologies participate in medicalisation through ever more sophisticated diagnostic tests that identify and quantify risks, predispositions and symptoms for medical treatment (Maturo et al. 2016; Lupton 2014; Rich and Miah 2014). Research into broader public culture, digital spaces and technologies has also identified the range of pressures, forces and negative effects on young people's well-being-intensified microaggressions of sexism, racism, trans/homophobia, Islamophobia etc., social comparison, body surveillance and the performative context of social media (Davies et al. 2015; Hendry et al. 2017; McCosker 2017; Swist et al. 2015). Yet to date, little of this work has engaged with pedagogically informed understandings of digital 
technologies to consider the plethora of ways in which young people are urged to learn about mental (ill-)health and how these pedagogies urge young people to enact particular modes of subjectivity.

\section{Digital Entanglements: Public Pedagogies of Mental Health}

There are two main bodies of literature and digital mental health practice that have emerged in the area of youth mental health with different pedagogic orientations: (1) pedagogies in what are seen as formal sites of learning, such as school education and public health promotion that seek to increase mental health literacy in relation to dominant classifications of mental illness (we explore this literature in the next section); and (2) informal and mobile digital mental health pedagogies that connect public and private, clinical and everyday spaces. For example, formal campaigns in the UK include the decade long anti-stigma promotion of Time to Change (with various digital platforms) and a range of school based initiatives seeking to increase mental health literacy. With regard to informal digital practices there are a growing number of commercial self-monitoring apps, online programmes such as 'moodgym' informed by cognitive behavioural therapy (CBT); and gamified CBT treatments for depression, such as SPARX [Smart, Positive, Active, Reality, X-Factor thoughts] - a first-person interactive game where self-created avatars fight GNATs [Gloomy, Negative, Automatic thoughts] (Merry et al. 2012). Whilst many of these technologies could seemingly be categorized as 'formal' or 'informal' public spaces, we are mindful of Savage (2010) critique that the term public, like pedagogy, has been used in totalizing ways, separating public from private and often disregarding "multiple and disparate publics" (p. 104). As such, we introduce a conceptual approach that aims to disrupt this false dichotomy between formal/informal.

There are also co-designed social marketing campaigns using various "participatory methods" with the desire to better engage young people in understanding and acting upon mental ill health (Spears et al. 2016). Awareness raising campaigns mobilise a range of digital practices, agencies and forms of engagement-webtext, interactive forums, vlogs, personal narratives-with orientations that range from individual behaviour change to the creation of networked publics (Swist and Collin 2017). The growth of campaigns (many combating stigma) that mobilise youth participation (through social media) is also bound up with the entrepreneurial imperatives of charities whose fundraising strategies are intertwined with the creation of new "publics" (on university student mental health charities, see Phillipson 2017). Within the informal sphere of digital mental health there is also an emerging literature that has begun to document the self-representation practices mobilised by young people (particularly young women around distress and disordered eating) as part of a broad spectrum of mental health "activism" via social media (Dobson 2015; Holmes 2016).

This diverse range of practices points to how the digital media landscape of mental health education and promotion is produced through a complex assemblage of agencies (government, commercial, charitable and activist), objects (policies, medication, images, phones) and individuals with diverse values, rationales, resources and forms of authority. Hence, mental health pedagogies that articulate biopsy expertise are not simply contained to formal educational sites, rather they also circulate notions of risk, illness and therapeutic culture through social media sites (vlogs, blogs, Instagram, forums etc.). These sites in turn mediate how young people articulate their experiences of distress via categories of depression, anxiety, disordered eating etc. (Hendry et al. 2017; Trnka 2016). Hence, the digital literacy and learning relations about mental health that young people are engaged through need to be understood as thoroughly entangled with diagnostic cultures, clinical expertise, activist movements, Big Pharma research and products, as well as formal education and public promotion campaigns. Analysing the modes of address that are deployed across government, charitable, activist and corporate forms of public pedagogy aimed youth mental health, requires some new ways of theorising the cultural work of pedagogy.

To better understand how learning about mental health is entangled with expert and lay knowledge, we draw upon the theoretical debates informing the field of public pedagogy. We reflect on "precisely how pedagogies are conceptualised and how these pedagogies are enacted" 
(Burdick and Sandlin 2013, p. 143) within these environments. As such, our examination of the public pedagogies of digital mental health is partly a response to the call from Burdick and Sandlin (2013) to offer clarity as to what is meant by pedagogy (see also Savage 2010; Sandlin et al. 2011). Scholarship focused on informal sites of learning (Ellsworth 2002, 2005), pedagogy writ large (Hickey-Moody et al. 2010) or public pedagogy (Sandlin et al. 2011), has drawn attention to the learning that takes place across a range of public sites and spaces. As Sandlin et al. (2011, p. 338) state, "this form of education, commonly known as public pedagogy, has been largely constructed as a concept focusing on various forms, processes and sites of education and learning occurring beyond formal schooling". Whilst 'public pedagogy' is a contested term there is however some general consensus within the field about the focus on 'learning' that takes place outside of formal schooling. At a time when digital tools are emerging as central to innovation in mental health care, and as techniques of governing (Rose and Abi-Rached 2013), important ethical questions arise about how public knowledge functions as pedagogy in personal-public lives. How young people are urged to become particular kinds of 'normal' subjects by learning how to act upon their 'abnormality'?

In turning our attention to the public pedagogies of mental health, we need be cautious of an all-encompassing notion of pedagogy that attempts "to capture anything and everything as remotely educative as pedagogical" (Gaztambide-Fernandez and Arraiz-Matute 2014, p. 52). Gaztambide-Fernandez and Arraiz-Matute (2014, p. 53) argue that "pedagogy always implies a relationship that is driven by intentions and desires for particular kinds of shifts in subjectivity" and "make the case for the articulation of an ethical imperative that is always the premise of any discussion about pedagogy." Taking this proposition seriously, we think through how these emerging digital mental health technologies constitute young people as pedagogical subjects who are expected to continually acquire appropriate self-knowledge. Furthermore, in our desire to think beyond the limitations of the humanist subject as the source of meaning and ideological power that is somehow free from materiality, we ask different questions concerning the affective relations between constitutive elements of public pedagogies. We examine the intent of education, the substance of learning and the embodied process of learning-knowing about mental ill health (Hickey-Moody et al. 2010).

\section{Thinking Public Pedagogy as Entangled Relations of Knowledge, Technology \& Affect}

Building on previous work (Fullagar 2018; Rich and Miah 2014), we explore the ways in which embodied subjects are connected through technology to material objects themselves and to other bodies, while questioning normative models of learning about mental health as "knowledge transfer." Through this posthumanist orientation our aim is to extend the conceptualization of a digital e-mental health ecosystem (Burns et al. 2016) by starting with different onto-epistemological assumptions about knowledge, technology and affect. Following the work of Barad (2007), we understand human-technological relations as co-implicated in producing (not merely representing) mental health phenomena that materialise through entanglements with digital texts, images, embodied histories and cultural norms of personhood. This digital eco-system is neither created by 'technology' (technological determinism), nor by 'people' (humanist). We aim to move beyond the polarised debate that assumes technology determines particular behaviours, or is a source of individual agency that somehow stands apart from sociomaterial relations. Instead, we consider these relationally, to understand the affordances and effects of digital intra-actions with mental health technologies. Later we discuss the limitations of key concepts - such as mental health literacy — that have ignored how learning about mental health involves a complex, digital negotiation of affects (shaming, stigmatising) that are personal, political and performed publicly in different ways (images on Instagram, text based interaction on forums, self-tracking and possible data sharing via apps).

Recent studies within the field of public pedagogy have begun to examine how users "interact with the public pedagogy of technological spaces" (Freishtat and Sandlin 2010, p. 503). We extend this work further to consider how intra-active pedagogies (Lenz Taguchi 2016) produce ways of enacting, knowing and performing certain kinds of (ab)normal personhood—ill and performing well, 
independent through reliance on professional advice to self-manage, autonomous via repertoires of sharing and improving cognitive capacity. Rather than document the meanings created by learners or produce analytical accounts of particular digital technologies, we consider how the human and non-human are co-implicated in the digitally mediated process through which learning about mental health materialises. In so doing we offer a conceptual approach to identify pedagogical modes of address that focus on what digital practices "do" and how they "act" to constitute experiences of subjectivity through the micropolitical intra-actions of everyday life (Barad 2007). In this way Barad (2007) shifts our thinking about the social world as primarily made up of "human interactions" between separate entities (individuals or objects) that pre-exist social and material relations by coining the term intra-action. She asks us to think ourselves as "of" the world, part of the lively and ongoing production of possibilities and exclusions, as digitally entangled (see also Lupton 2017). Materiality matters not as an add-on to language, not as a matter of language, but because the material, affective and embodied can never be separate from language (on the materiality of mental health see (Fullagar 2018)). For example, when young people are urged in public campaigns (such as Time to Change, England) to speak back to the stigma and discrimination surrounding mental health problems, a certain performance of individual resistance is evoked against the silence and negative effects that cohere around a predominantly 'illness' focused identity. While the intention of such pedagogies is to encourage the stance of active learning to challenge the othering of mental illness identities, stigma is positioned as a response to a form of 'difference' from normality that is not yet accepted in comparison to physical illness. In this formulation, there is little questioning of 'how' knowledge about mental ill health and stigma are produced as biomedical phenomena entangled with diagnostic practice and aetiology (faulty biochemistry, lack of cognitive coping skills, genetic inheritance). Hence, learning to challenge cultural attitudes to stigma is premised upon understanding the problem of mental ill health 'within' the person. The popularity of sharing personal testimonies about lived experiences of distress and recovery through vlogs and blogs points to how digital practices are co-implicated with particular mental health pedagogies (biomedical, resistant and confessional modes of address). What often remains 'silenced' by such modes of address are the more complex social, political, economic and historical relations that shape how stigma and mental ill health materialize in the context of individual and population patterns with respect to gender, class, ethnicity, sexuality etc. These are ethical questions about how pedagogies of mental health "cut" —or produce-individual and cultural understandings, actions and institutional responses.

Extending the work of Michel Foucault and Judith Butler, Barad (2007, p. 141) argues for a post-humanist performativity of which "all bodies, not merely 'human' bodies, come to matter through the world's iterative intra-activity -its performativity." Barad (2003) onto-epistemology is also organised around ethical concerns with "accountability" that relate to identifying how "cuts" are made through the very material-discursive practices of all research and knowledge production (from theories and research methods, to policies and pedagogies). In terms of exploring the materiality of mental health pedagogies, Barad's work orients us towards the boundaries that are produced by certain "cuts" in the intra-actions of digital practices and the embodied subjectivities of young people (the patterns and affective connections that produce effects). As Trnka (2016, p. 250) argues in relation to the temporality and immediacy of digital technology for young people, "health apps heighten and intensify both self-focused and interpersonal dynamics of care." We expand on this by recognizing how these practices are promoted through pedagogies of mental health and necessitate ongoing acts of learning to improve oneself.

Extending the insights of this body of work we propose an analytic approach that engages critically with the exploration of different pedagogies of mental health to contribute to "an account of the desires, intentions and conditions that produce them as such" (Gaztambide-Fernandez and Arraiz-Matute 2014, p. 57). From a posthumanist perspective, desire and intentionality are not centred within the human subject, rather they are forces of affect that shape meaning through an assemblage of relations, objects and historical practices. Slaby et al. (forthcoming) 
use the Deleuzian term 'affective arrangement' to emphasise the relations of affect that exist beyond individualised emotion, and yet connect individuals within a wide range of sociomaterial objects and practices. They state that "an affective arrangement is an analytical tool to flesh out how affect unfolds dynamically and often unpredictably in a relational setting, while it is yet framed and modulated in recurring and structured ways" (Slaby et al. forthcoming).

Public pedagogy in this sense is enacted through particular intensities and relations that produce particular "cuts" which in turn frame learning and knowing in ways that recur and also disrupt. This is an ethical question concerning how public pedagogies of mental health work through particular logics, materialities and affects to re-inscribe, - or counter-medicalised, psychologised and normalised articulations of youth subjectivities? Such an approach brings into relation the economic, visceral, political, affective, technomaterial and sociocultural forces that configure learning around the problematic of understanding and responding to emotional distress as a marker of normal or abnormal, ill or well subjectivity. Digital practices can engage young people in ways of knowing that can regulate and medicalise or open up new possibilities for understanding what embodied affects "do" across the spectrum of emotions from despair to pleasure. Fox (2015, p. 308) posthumanist perspective foregrounds the affective flows that shape the agency of learners and places emphasis on,

assemblages of human and non-human relations rather than upon individual 'emotional' bodies; on flows of affect within assemblages rather than notions of agency attached to humans; and on territorializations and de-territorializations of capacities to do and feel rather than deterministic social structures and fields.

Tucker and Goodings $(2016,2017)$ also argue in their study of embodied accounts of medication use in an online mental health forum (Elefriends, London, UK) that more attention needs to be paid to the affective power of digital media and the individual "search for intensity," amongst others (Passonen 2015). To counter individualised and disembodied accounts of mental ill health they point to "the socio-material conditions of existence of distress in which people develop an affectual relationship with themselves (knowing from within), the site itself (body-technology) and other users of Elefriends (social relations)" (Tucker and Goodings 2016, p. 12). This approach could open lines of inquiry about the multiple practices of learning that emerge through such entanglements and registering the capacities and potentialities of such learning (for example, creating different ontologies of becoming-knowing, see Fullagar et al. this issue).

Feminist scholars have also begun to explore the performative nature of emotional distress and recovery cultures within the complex digital entanglement of normative and resistant ways of knowing the self (on anorexia YouTube sites, see Holmes 2016; Lamarre and Rice 2017 in this issue). These multiple ways of knowing (normative, medicalised, social, critical) work to complicate any assumptions about unified subjectivity or agentic selfhood that underpin conventional models of mental health literacy aimed at educating for better health or illness reduction. Within the context of cultures of connectivity (Van Dijck 2013), this means focusing on the relationality between technology, its production and its reception as pedagogical. Given that digital mental health practices generate intersecting publics across multiple platforms, one of the challenges involves understanding the extent to which pedagogical forces create publics by extending and linking people together (Savage 2010). Another challenge is understanding how young people enact their emotions, identities and (ill-)health in relation to materiality of digital relations experienced through family, gender, class, race, sexuality, etc. Next we turn to critically consider the assumptions that inform increasingly commonplace notions of mental health literacy.

\section{Expert Pedagogies of Mental Health Literacy}

The concept of mental health literacy (Kelly et al. 2007) has emerged as area of psychological research that articulates and measures what citizens must know in order to understand their distress and seek help. Such research has informed the rise of various public education programmes, such as 
Mental Health First Aid (with a youth focused version), for improving the mental health literacy of people giving and receiving support. However, research on mental health literacy has rarely asked more critical questions about the material and discursive relations that shape how learning occurs about complex issues related to mental health as a sociocultural phenomenon (DeFehr 2016). Notions of mental health literacy typically promoted in mental health policy and interventions are underpinned by humanist assumptions about education and subjectivity. Hence, they privilege knowledge transmission models where learners "acquire" new information, realist forms of representation (expert truths about mental illness are correct) and perpetuate limited assumptions about rational subjectivity. Having "good" mental health literacy-e.g. knowing the symptoms of depression and complying with expert notions of what constitutes appropriate treatment-is premised on a "foundational understanding of educational activity" (Burdick and Sandlin 2013, p.145). This orientation to learning "targets the self, or more specifically the western notion of the self as developmental, autonomous, and rational isolate, as the object of pedagogical and curricular energies" (Burdick and Sandlin 2013, p.145). Such educational interventions thus promote highly individualised forms of cognitively oriented "knowledge" by emphasising the acquisition of information about risk factors, help-seeking, peer support and self-management behaviours, thus bracketing out the sociocultural relations of affect (such as the shame or despair associated with failing to meet normative, consumerist ideals).

Young people's learning about mental health is bound up with expert pedagogies that circulate truths about normal/abnormal experiences of distress through public and institutionalised spaces (clinics, policy discourses, mental health promotion, professional education). Public pedagogies work to mediate how emotional distress is rendered knowable as phenomena via instructional logics and diagnostic classification of somatic symptoms (what is wrong with me) identified as psychopathologies (who I am)-depression, anxiety, eating disorders, schizophrenia. Ecclestone and Goodley (2016) have argued that such power relations work through individualising notions of "vulnerability" that connect youth identities, issues of low self-esteem, risk, marginalisation and calls for the development of greater resilience as a manifestation of "therapeutic culture".

In formal pedagogical sites, Gagen (2015) argues that the growth of emotional literacy programmes in UK schools is problematic because vocabularies of mental health are articulated through discourses of neuroscience and brain dysfunction. Experiences of distress, effects of inequality and uncertainty for contemporary subjects become framed in terms of neuroselfhood where learning about oneself is mediated through a molecular gaze on the brain and psychological dysfunction (Rose and Abi-Rached 2013). Learning about mental health becomes bound up with the linear assumptions of biopsycho causality (problems are caused by brain dysfunction) that reconfigure the social forces undermining well-being as individual problems. These neuropedagogies (as a specific intra-action of psycho and biopedagogies) actively shape how emotional distress comes to materialise through the mediations of diagnostic culture that commonly deploys mental illness identities. Truths about the ill self materialise via ubiquitous images of brain scans that figure as evidence across multiple sites of learning, such as early years education, child welfare, and mental health policies (Lenz Taguchi 2016).

In addition, the syndromisation of mental illness has multiplied the number of disorders and increased the chances for a patient to receive a diagnosis (Maturo et al. 2016). Starting from the third edition of the DSM diagnoses are increasingly based on the number and duration of symptoms (if five of nine symptoms persist for more than four weeks you should see a doctor)—and have abandoned the indeterminacy and complexity of psychoanalytic jargon (Maturo et al. 2016). Numbers are more "palatable" for constructing a diagnosis (Horwitz and Wakefield 2009; Jutel and Lupton 2015). Therefore, subjective sensations are easily transformed — through the "objectivity" of numbers-into clear-cut "scientific" diagnosis. Once quantification algorithms become codified and routinized their products are reified and become "real". In this way, digitalisation and self-tracking practices have acted as an engine of medicalisation, along with the robust trend of quantification that characterises part of contemporary society (Maturo et al. 2016). How such processes work through bodies, affective 
intensities, and hence more digitally dispersed notions of agency are questions that move us beyond the medicalisation thesis.

The therapeutic and biomedical expertise of mental health education 'promises' individuals a sense of certainty and empowerment through self-knowledge, which is produced against the relations of affect that are bound up with stigma and the complex conditions shaping distress (fear, anxiety, shame, disaffection). Hence, neuropedagogies of mental health act in a performative sense to articulate solutions in terms of correction and cure through psychopharmacology and behavioural self-management practices. The at-risk or recovering self is urged to learn various techniques to manage and reduce symptoms related to the mind (CBT techniques) and body (exercise, sleep, eating patterns) in the pursuit of normalized ideals of personhood in advanced liberalism (productive, entrepreneurial, successful selves). The organization of these mental health pedagogies contributes to a form of pedagogic address through instructional devices that is underpinned by 'expert' knowledge, providing the means through which the recovering self can not only acquire this knowledge, but also engage in "moral selving" (Barnett et al. 2005). Rose argues that, "In striving to live our autonomous lives, to discover who we really are, to realize our potentials and shape our lifestyles, we become tied to the project of our own identity and bound in new ways into the pedagogies of expertise" (Rose 1999, p. 93). In the context of ubiquitous lifestyle advice (apps, webforums, blogs, promotional campaigns) it is very difficult for young people struggling with distress and despair to untangle themselves from the intent of expert pedagogies to identify, educate, treat and restore "mental health" that is defined through and against "abnormality" positioned within the self as illness, deficit and disorder.

We argue that expert pedagogies of mental health literacy fail to identify the ethical implications of the "cuts" that they produce in representations of learning as primarily cognitive, based on binaries of health and illness, and disconnected from the social conditions that govern young people's distress. The reliance upon such limited notions of literacy in mental health education and promotion means that a more complex understanding of the relations of affect entangling public and personal lives is rarely explored. At the heart of many well intended mental health education interventions is an ethical issue about whether discourses of normality/abnormality are simply reiterated and hence the power relations that enable distress to flourish remain obscured (Fullagar 2008). Within Fullagar et al. (forthcoming) this issue we analyse how such expertise authorises certain pedagogical modes of address via mental health apps within the broader affective arrangement of digital mental health. This work mobilises our conceptual framework in an analysis of selected mental health 'apps' and social media.

\section{Concluding Remarks}

Across a range of disciplines there is a growing critique of the ways in which "expert solutions" to emotional distress are permeating formal and informal pedagogic sites in calls for alternative, critical practice and cultural frameworks (Ecclestone and Goodley 2016; Gagen 2015; Wiener 2005). In this regard, our focus on public pedagogy offers a useful way of connecting different debates about the impacts, intentions and transformations of digital mental health technologies in different contexts. For example, Canadian scholars White et al. (2012) have identified the limitations of mental health literacy in school-based youth suicide prevention programmes and argue for a critical sensibility that does not assume coherence, knowledge hierarchies or stable cultural understandings about distress or help-seeking practices. Through a different focus, literacy scholars have pursued onto-epistemological questions that could inform new ways of approaching mental health literacy beyond transmission models. For example, Burnett et al. (2014, p.101) offers an analytic focus that brings "together notions of the sensory, unfolding material world and the multimodal, textual and 'imagined' digital world, the (im)materialities lens helps us see literacy as multiply and flexibly situated." Feminist education scholars are also making visible the gendered relations and normative practices within and beyond schools that position girls in affective economies where the 
conditions for harassment, shaming, perfectionism and distress can flourish (Lenz Taguchi 2016; Ringrose and Renold 2014; Lenz Taguchi and Palmer 2013).

In providing a conceptual approach to exploring how formal and informal pedagogical sites for learning about youth mental (ill) health are producing new kinds of (ab)normal in the digital era, we have brought together critical debates on public pedagogy with digital health. This allows for an examination of how pedagogic modes of address are co-implicated in the political, economic, material and discursive relations of digital mental health that is usefully understood as an "affective arrangement" of learning-knowing (Slaby et al. forthcoming). Such an approach assumes that neither the users, nor the technologies themselves (e.g. apps) can be considered to have particular attributes, but rather they are thought together in terms of emerging capacities which are shaped by a pedagogical orientation. Such perspectives can reveal how particular young people experiencing distress may be encouraged to learn particular self-care practices encouraged by neoliberal notions of the rationalist learner and subject.

While we are interested in the micropolitics of digital practices this is not to suggest that youth participation can be made sense of as purely a local, individualised practice. Rather, as Fox et al. (2016, p. 5) suggest, "it is important to acknowledge that what might seem like a local event is often part of a much broader assemblage, mediated through the multiplicity of each relation's affective connections." Thus, we argue for a more nuanced understanding of the entangled intra-actions of public and private, expert and lay knowledge, and normal and abnormal selfhood that operate through particular digital economies. We agree with Savage (2010, p. 105) suggestion that "surely the ways young people learn cannot be understood without recognizing the power of local spaces to mediate the ways forms of knowledge are received and experienced." This also means understanding the ways in which such pedagogies are also appropriated in critical and sometimes resistant ways by the young people who engage with them. Further research is needed to identify how these assemblages therefore unfold in ways that provide possibilities for refiguring subjectivity beyond individualised, biomedical understandings. Digital pedagogies are part of these open assemblages, continually unfolding as people engage in different ways, thus challenging the idea of pedagogy and learner as separate entities.

The publicness of such pedagogic relations is not simply a given, rather it is produced through the affordances of sociomaterial practices that enable the historically private experiences of "actors and events to become public" (Biesta 2012, p. 693). As such, we recognize that agency is not located within the individual. Instead we find value in thinking about how to conceptualise agency as dispersed and constituted through assemblages that simultaneously open up lines of becoming and also reterritorialise knowledges, identities and practices (Fox 2015).

Advocating a "relationality-as-pedagogy" approach, Burdick and Sandlin (2013) articulate a post-humanist notion of critical public pedagogy as rupture, interruption and as event (Biesta 2012, p. 693). In Barad (2012, p. 1) terms our analysis of pedagogic interruptions involves "diffractive readings [that] bring inventive provocations; they are good to think with. They are respectful, detailed, ethical engagements". In this way, our approach moves beyond any simple opposition between biomedical-expert and youth-resistant pedagogies of mental health. Pedagogies materialize through traces that are entangled with expert, normative, subjugated and counter knowledges of mind-body, self-world, private-public relations. This relational perspective provides space for the "the concept of the unknown and unknowable as a key element of critical pedagogical exchange" (Burdick and Sandlin 2013, p. 172). Our conceptualisation of public pedagogy is, as such, as a site of multiplicity, a set of performative practices that enact (rather than merely represent truths) about what it means to experience emotional distress and be identified as having a mental health problem.

We are left with a number of questions for future exploration, including how the emerging terrain of digital mental health opens up spaces for organisations, individuals, and fluid publics (a far from exhaustive list) to produce alternative pedagogies that grapple with the ethical questions we have raised. And conceptually, how might a posthumanist perspective on public pedagogy enable a closer examination of the materiality and micropolitics of mental health knowledge claims that seek to "help," 
"intervene," or "transform" public awareness and understanding of key issues? Whilst we have begun to highlight some potential lines of inquiry, these questions illustrate the need for "new theoretical assemblages that facilitate interdisciplinary forms of inquiry" (Hickey-Moody 2014, p. 2) into young people's learning about mental health through digital health technologies.

Author Contributions: All authors contributed to the collection and analysis of digital mental health examples, the review of the literature, and this was undertaken collaboratively and iteratively. The writing process was led by the first author, with the second and third authors contributing to the development of the argument and the review of the literature.

Conflicts of Interest: The authors declare no conflict of interest.

\section{References}

Barad, Karen. 2003. Posthumanist performativity: Toward an understanding of how matter comes to matter. Signs: Journal of Women in Culture and Society 28: 801-31. [CrossRef]

Barad, Karen. 2007. Meeting the Universe Halfway: Quantum Physics and the Entanglement of Matter and Meaning. Durham: Duke University Press.

Barad, Karen. 2012. Matter feels, converses, suffers, desires, yearns, and remembers. In New Materialism: Interviews and Cartographies. Edited by Rick Dolphijn and Iris van der Tuin. London: Open Humanities Press. Available online: http:/ / quod.lib.umich.edu/o/ohp/11515701.0001.001/1:4.3/-new-materialisminterviews-cartographies?rgn=div2; view=fulltext (accessed on 4 May 2017).

Barnett, Clive, Paul Cloke, Nick Clarke, and Alice Malpass. 2005. Consuming ethics: Articulating the subjects and spaces of ethical consumption. Antipode 37: 23-45. [CrossRef]

Biesta, Gert. 2012. Becoming public: Public pedagogy, citizenship and the public sphere. Social E Cultural Geography 13: 683-97.

Burdick, Jake, and Jennifer Sandlin. 2013. Learning, becoming and the unknowable: Conceptualizations, mechanisms and the process in public pedagogy literature. Curriculum Inquiry 43: 142-77. [CrossRef]

Burnett, Cathy, Guy Merchant, Kate Pahl, and Jennifer Rowsell. 2014. The (im)materiality of literacy: The significance of subjectivity to new literacies research. Discourse: Studies in the Cultural Politics of Education 35: 90-103. [CrossRef]

Burns, Jane M., Emma Birrell, Marie Bismark, Jane Pirkis, Tracey Davenport, Ian Hickie, Melissa Weinberg, and Louise Ellis. 2016. The role of technology in Australian youth mental health reform. Australian Health Review 40: 584-90. [CrossRef] [PubMed]

Chris Davies, John Coleman, and Sonia Livingstone, eds. 2015. Digital Technologies in the Lives of Young People. London: Routledge.

DeFehr, Jan Nadine. 2016. Inventing Mental Health First Aid: The problem of psychocentrism. Studies in Social Justice 10: 18-35. [CrossRef]

Dobson, Amy Shields. 2015. Girls' 'pain Memes' on YouTube: The Production of Pain and Femininity in a Digital Network. In Youth Cultures and Subcultures: Australian Perspectives. Edited by Sarah Baker, Brady Robards and Bob Buttigieg. Farnham: Ashgate, pp. 173-81.

Duff, Cameron. 2014. Assemblages of Health: Deleuze's Empiricism and the Ethology of Life. Rotterdam: Springer.

Ecclestone, Kathryn, and Daniel Goodley. 2016. Political and educational springboard or straitjacket? Theorising post/human subjects in an age of vulnerability. Discourse: Studies in the Cultural Politics of Education 37: 175-88. [CrossRef]

Ellsworth, Elizabeth Ann. 2002. The US Holocaust Museum as a Scene of Pedagogical Address. Symploke 10: 13-31. [CrossRef]

Ellsworth, Elizabeth Ann. 2005. Places of Learning: Media, Architecture, Pedagogy. New York: Routledge.

Fox, Nick J. 2015. Emotions, Affects and the Production of Social Life. The British Journal of Sociology. [CrossRef] [PubMed]

Fox, Nick, Paul Bissell, Marian Peacock, and Joanna Blackburn. 2016. The Micropolitics of Obesity: Materialism, Markets and Food Sovereignty. Sociology. [CrossRef]

Freishtat, Richard L., and Jennifer A. Sandlin. 2010. Shaping youth discourse about technology: Technological colonization, manifest destiny, and the frontier myth in Facebook's public pedagogy. Educational Studies 46: 503-23. [CrossRef] 
Fullagar, Simone. 2008. Sites of somatic subjectivity: E-scaped mental health promotion and the biopolitics of depression. Social Theory E Health 6: 323-41.

Fullagar, Simone. 2017. Foucauldian Theory. In Routledge International Handbook of Critical Mental Health. Edited by Bruce Cohen. London: Routledge.

Fullagar, Simone. 2018. Diffracting mind-body Relations: Feminist materialism and the entanglement of physical culture in women's recovery from depression. In Moving Body: Sporting Ecologies, Assemblages, and New Materialisms. Edited by Josh Newman, Holly Thorpe and David Andrews. New Brunswick: Rutgers University Press, in press.

Fullagar, Simone, Emma Rich, Jessica Francombe-Webb, and Antonio Maturo. Forthcoming. Youth mental health in the digital age: Understanding public pedagogies as affective arrangements. Social Sciences.

Gagen, Elizabeth A. 2015. Governing emotions: Citizenship, neuroscience and the education of youth. Transactions of the Institute of British Geographers 40: 140-52. [CrossRef]

Gaztambide-Fernandez, Ruben, and Alexandra Arraiz-Matute. 2014. "Pushing Against": Relationality, Intentionality, and the Ethical Imperative of Pedagogy. In Problematizing Public Pedagogy. Edited by Jake Burdick, Jennifer Sandlin and Michael O'Malley. New York: Routeldge, pp. 52-64.

Giroux, Henry A. 2004. Cultural Studies and the Politics of Public Pedagogy: Making the Political More Pedagogical. Parallax 10: 73-89. [CrossRef]

Hendry, Natalie A., Brady Robards, and Sonya Stanford. 2017. Beyond Social Media Panics for 'at Risk' Youth in Mental Health Practice. In Beyond the Risk Paradigm in Mental Health Policy and Practice. Edited by Sonya Stanford, Elaine Sharland, Nina Rovinelli Heller and Joanne Warner. Houndsmills: Palgrave Macmillan, pp. 135-54.

Hickey-Moody, Anna. 2014. Youth, Arts and Education: Reassembling Subjectivity through Affect. Oxford and New York: Routledge.

Hickey-Moody, Anna, Glenn C. Savage, and Joel Windle. 2010. Pedagogy Writ Large: Public, Popular and Cultural Pedagogies in Motion. Critical Studies in Education 51: 227-36. [CrossRef]

Holmes, Su. 2016. 'My anorexia story': Girls constructing narratives of identity on YouTube. Cultural Studies, 1-23. [CrossRef]

Horwitz, Allan, and Jerome Wakefield. 2009. The medicalization of sadness. Salute e Società 8: 49-66.

Jutel, Annamarie, and Deborah Lupton. 2015. Digitizing diagnosis: a review of mobile applications in the diagnostic process. Diagnosis 2: 1-8. [CrossRef]

Kelly, Claire M., Anthony F. Jorm, and Annemarie Wright. 2007. Improving mental health literacy as a strategy to facilitate early intervention for mental disorders. Medical Journal of Australia 187: S26-S30. [PubMed]

Lamarre, Andrea, and Carla Rice. 2017. Hashtag Recovery: \#Eating Disorder Recovery on Instagram. Social Sciences 6: 68. [CrossRef]

Lenz Taguchi, Hillevi. 2016. Deleuzo-Guattarian Rhizomatics: Mapping the Desiring Forces and Connections between Educational Practices and the Neurosciences. In Posthuman Research Practices in Education. Edited by Alicia Youngblood Jackson and Christina Hughes. London: Palgrave Macmillan, pp. 37-57.

Lenz Taguchi, Hillevi, and Anna Palmer. 2013. A more 'livable' school? A diffractive analysis of the performative enactments of girls' ill-/well-being with (in) school environments. Gender and Education 25: 671-87. [CrossRef]

Lupton, Deborah. 2014. Apps as Artefacts: Towards a Critical Perspective on Mobile Health and Medical Apps. Societies 4: 606-22. [CrossRef]

Lupton, Deborah. 2017. Data thing-power: How do personal digital data come to matter? SSRN. June, pp. 1-16. Available online: https:// papers.ssrn.com/sol3/papers.cfm?abstract_id=2998571 (accessed on 4 August 2017).

Maturo, Antonio, Luca Mori, and Veronica Moretti. 2016. An Ambiguous Health Education: The Quantified Self and the Medicalization of the Mental Sphere. Italian Journal of Sociology of Education 8: 248-68.

McCosker, Anthony. 2017. Digital mental health and visibility: Tagging depression. In Digital Media: Transformations in Human Communication, 2nd ed. Edited by Paul Messaris and Lee Humphrey. New York: Peter Lang, pp. 31-39.

McManus, Sally, Paul Bebbington, Rachel Jenkins, and Terry Brugha. 2016. Mental Health and Wellbeing in England: Adult Psychiatric Morbidity Survey 2014. Leeds: NHS Digital. Available online: http:/ / content.digital.nhs.uk/ catalogue/PUB21748 (accessed on 5 July 2017). 
Merry, Sally N., Karolina Stasiak, Matthew Shepherd, Chris Frampton, Theresa Fleming, and Mathijs Lucassen. 2012. The effectiveness of SPARX, a computerised self help intervention for adolescents seeking help for depression: Randomised controlled non-inferiority trial. British Medical Journal 344: e2598. [CrossRef] [PubMed]

Passonen, Sussana. 2015. A midsummer's bonfire: Affective intensities of online debate. In Networked Affect. Edited by Ken Hills, Sussana Passonen and Michael Petit. Cambridge: MIT Press, pp. 27-43.

Phillipson, Andrea. 2017. Incorporated: Student Mental Health Discourse and Higher Education in Canada. Ph.D. thesis, Queen's University, CA, USA.

Rich, Emma, and Andy Miah. 2014. Understanding digital health as public pedagogy: A critical framework. Societies 4: 296-315. [CrossRef]

Ringrose, Jessica, and Emma Renold. 2014. “F**k Rape!": Exploring affective intensities in a feminist research assemblage. Qualitative Inquiry 20: 772-80. [CrossRef]

Rose, Nikolas. 1999. The Powers of Freedom: Reframing Political Thought. Cambridge: Cambridge University Press.

Rose, Nikolas, and Joelle Abi-Rached. 2013. Neuro: The New Brain Sciences and the Management of the Mind. Princeton: Princeton University Press.

Sandlin, Jennifer, Michael O'Malley, and Jake Burdick. 2011. Mapping the complexity of public pedagogy scholarship 1894-2010. Review of Educational Research 81: 338-75. [CrossRef]

Savage, Glenn. 2010. Problematising 'public pedagogy' in educational research. In Handbook of Public Pedagogy: Education and Learning beyond Schooling. Edited by Jennifer A. Sandlin, Brian D. Schultz and Jake Burdick. New York: Routledge, pp. 103-15.

Slaby, Jan, Rainer Mühlhoff, and Philipp Wüschner. Forthcoming. Affective Arrangements. Working Paper. Available online: https://www.academia.edu/24433992/Affective_Arrangements (accessed on 19 May 2017).

Spears, Barbara, Carmel Taddeo, Alan Barnes, Philippa Collin, Teresa Swist, Jane Webb-Williams, Cindy Brock, Phillip Kavanagh, and Judy Drennan. 2016. Something Haunting You? Reframing and Promoting Help-Seeking for Young Men: The Co-Creation and Evaluation of a Social Marketing Campaign. Melbourne: Young and Well Cooperative Research Centre.

Swist, Teresa, and Philippa Collin. 2017. Platforms, Data and Children's Rights: Introducing a 'networked Capability Approach'. New Media \& Society 19: 671-85.

Swist, Theresa, Philippa Collin, Jane McCormack, and Amanda Third. 2015. Social Media and the Wellbeing of Children and Young People: A Literature Review. Perth: Prepared for the Commissioner for Children and Young People, Western Australia.

Trnka, Susanna. 2016. Digital Care: Agency and Temporality in Young People's use of Health Apps. Engaging Science, Technology, and Society 2: 248-65. [CrossRef]

Tucker, Ian M., and Lewis Goodings. 2016. Medicated bodies: Mental distress, social media and affect. New Media and Society. [CrossRef]

Tucker, Ian M., and Lewis Goodings. 2017. Digital atmospheres: Affective practices of care in Elefriends. Sociology of Health $\mathcal{E}$ Illness 39: 629-42.

Van Dijck, José. 2013. The Culture of Connectivity: A Critical History of Social Media. Oxford: Oxford University Press.

White, Jennifer, Jonathan Morris, and Hinbest Jerry. 2012. Collaborative knowledge-making in the everyday practice of youth suicide prevention education. International Journal of Qualitative Studies in Education 25: 339-55. [CrossRef]

Wiener, Diane. 2005. Antipsychiatric activism and feminism: The use of film and text to question biomedicine. Journal of Public Mental Health 4: 42-47. [CrossRef]

World Health Organisation. 2017. Depression and Other Common Mental Disorders: Global Health Estimates. Geneva: WHO.

(C) 2017 by the authors. Licensee MDPI, Basel, Switzerland. This article is an open access article distributed under the terms and conditions of the Creative Commons Attribution (CC BY) license (http://creativecommons.org/licenses/by/4.0/). 